\title{
Percepção do cuidado em saúde no CAPSad: uma visão do paciente
}

\author{
Maria Zilma Lima', Edilson Martins Rodrigues Neto², Marcia Oliveira Coelho³, \\ Lidia Audrey Rocha Valadas Marques ${ }^{4}$, Mara Assef Leitão Lotif ${ }^{4}$
}

\section{RESUMO}

Os Centros de Atenção Psicossocial Álcool e Drogas (CAPSad) são serviços de saúde mental destinados a oferecer a seus usuários um programa de cuidados intensivos, elaborado por uma equipe multidisciplinar. Este estudo tem como objetivo realizar uma apreciação do atendimento prestado pelos profissionais de saúde ao usuário, sendo objeto desse estudo pessoas com problemas decorrentes do uso prejudicial de álcool. Buscou-se compreender o modelo de cuidado em saúde do CAPSad na percepção dos usuários alcoolistas. Trata-se de uma pesquisa descritiva com abordagem qualitativa, realizada no Centro de Atenção Psicossocial, localizado na Secretaria Executiva Regional IV, do município de Fortaleza-CE. Procedimentos Metodológicos: foram desenvolvidas entrevistas semiestruturadas. Os dados foram submetidos à análise de conteúdo categorial temática. Foram definidas cinco categorias temáticas: fluxo do usuário na efetivação do atendimento no CAPSad; a relação entre o profissional do CAPSad e os usuários; orientações para os usuários; percepção dos usuários desenvolvida nas oficinas terapêuticas; participação do usuário no projeto terapêutico. Mediante análise de cada categoria, pôde-se apreender consistentes informações sobre os participantes e o significado por eles atribuídos a suas experiências e perceptivas naquele centro. Concluise que 0 acolhimento no CAPSad como instrumento de trabalho envolve todos os membros da equipe, favorecendo assim a resolubilidade da assistência, fato que é evidenciado pelo discurso dos pacientes durante as entrevistas.

Descritores: Serviços de Saúde Mental; Saúde Mental; Alcoolismo.

\section{Perception of health care in CAPSad: a vision from patient}

\begin{abstract}
The Psychosocial Care Centers Alcohol and Drugs (CAPSad) are mental health services to offer their users a program of intensive therapy, developed by a multidisciplinary team. This study aims to conduct an assessment of the care provided by health professionals to the user, the object of this study, people with problems arising from the harmful use of alcohol. We sought to understand the model of health care in the CAPSad perception of alcoholics users. This is a descriptive qualitative research conducted in Psychosocial Care Center, located in the Regional Executive Secretary IV, the city of Fortaleza. Methodological Procedures: Semi-structured interviews were developed. Data were submitted to analysis of categorical thematic content. User flow in effecting service in CAPSad, the relationship between the professional and the CAPSad users; guidelines for users; perception of users in developed therapeutic workshops, user participation in therapeutic project: five thematic categories were defined. Through analysis of each category, we could apprehend consistent information about the participants and the meaning they attributed their experiences and perceptive this center. It is concluded that the host in CAPSad as a working tool involves all team members, thus favoring the solvability of assistance, a fact that is evidenced by the speech of patients during interviews.
\end{abstract}

Descriptors: Mental Health Services; Mental Health; Alcoholism.

${ }^{1}$ Especialista em Saúde Pública pela Universidade Estadual do Ceará (UECE), Fortaleza, CE, Brasil.

${ }^{2}$ Mestre em Farmacologia pela Universidade Federal do Ceará (UFC), Fortaleza, CE, Brasil.

${ }^{3}$ Mestre em Saúde Pública pela Universidade Estadual do Ceará (UECE), Fortaleza, CE, Brasil.

${ }^{4}$ Especialista em Farmacologia Clínica pelo Instituto Ateneu, Fortaleza, CE, Brasil. 


\section{Introdução}

De acordo com o segundo Levantamento Domiciliar Nacional sobre o Uso de Drogas Psicotrópicas no Brasil envolvendo 149 municípios, com mais de 200 mil habitantes, a estimativa da população dependente de álcool foi de 11.700 .000 pessoas ${ }^{1}$.

A dependência do álcool gera sérios problemas físicos, psicológicos e sociais. No Brasil, transtornos decorrentes do uso de álcool são a terceira causa de aposentadoria por invalidez e ocupam o segundo lugar entre os demais transtornos mentais e debilidades².

É preciso compreender os efeitos do alcoolismo sobre as diversas interações sociais do indivíduo, onde compromete as relações sociais fundamentais, como as familiares, ou interfere no cumprimento de papéis básicos, como o de trabalhador e chefe de família ${ }^{3}$.

Culturalmente, a bebida alcoólica pode ser vista como um agente produtor de sociabilidade, ao qual é agregado um valor positivo. No entanto, para uma parcela da população, ela é um agente de dissociação, apresentando-se como um fator para rupturas das relações sociais, familiares e trabalhistas ${ }^{4}$.

O Sistema Único de Saúde (SUS) deve garantir atenção especializada aos usuários de álcool e outras drogas. Nesse âmbito, as diretrizes da política setorial de saúde preveem a implementação de Centros de Atenção Psicossocial Álcool e outras Drogras (CAPSad), atuando em uma rede para prover assistência aos usuários de álcool e outras drogas ${ }^{5}$.

Os CAPSad são unidades de atendimento em saúde mental que oferecem a seus usuários um programa de cuidados intensivos, elaborado por uma equipe multidisciplinar. Os Centros de Atenção Psicossociais (CAPS) foram configurados como alternativas terapêuticas ao modelo de tratamento centrado em hospitais psiquiátricos. Desde 2002, os CAPS atuam articulando a atenção em saúde com a comunidade, promovendo a vida comunitária e a autonomia dos seus usuários ${ }^{6}$.

Nesse contexto, é importante que essas práticas de cuidado sejam estimuladas e avaliadas, propondo a otimização dos investimentos financeiros públicos na construção de um sistema complexo, evitando, assim, a substituição de um modelo centralizador por outro?.

Os CAPSad devem atuar de forma articulada a outros dispositivos assistenciais em saúde mental (ambulatórios, leitos em hospital-geral, hospitais-dia) e da rede básica de saúde (unidades básicas de saúde etc.), bem como a Estratégia de Saúde da Família (ESF) e ao Programa Agentes Comunitários de Saúde (PACS). Assim os Centros se associam aos recursos de suporte sociais já existentes nas comunidades em que se inserem, caracterizando redes flexíveis de cuidados capazes de atender as demandas de determinado território. Essas redes se remodelam de forma dinâmica, de acordo com a necessidade de serviços e a demanda assistencial ${ }^{6}$.

Ademais, os dependentes químicos usuários dos CAPS têm acesso a atendimento ambulatorial diariamente. São realizados atendimentos individuais para administração de medicação, realização de psicoterapia e orientação, além de atendimentos em grupo ou oficinas terapêuticas e visitas domiciliares. Os usuários também podem repousar nos centros, bem como realizar desintoxicação ambulatorial, quando a desintoxicação a nível hospitalar é dispensável ${ }^{6}$.

Os CAPSad desempenham um importante papel de ordenar a rede de atendimento aos usuários de álcool e outras drogas em seu território de atuação, estimulando a articulação entre os dispositivos comunitários sociais e de saúde para permitir a atenção integral e inclusão social dos usuários e seus acompanhantes ${ }^{5}$.

Para atuar adequadamente, os CAPS devem contar com espaço próprio e especialmente preparado para atender à sua demanda específica, sendo capazes de proporcionar um ambiente continente e estruturado.

Como proposto pelo Ministério da Saúde,

O atendimento deverá ser realizado em um "meio terapêutico", isto é, tanto sessões individuais ou grupais como a convivência no serviço têm finalidade terapêutica. Isso é obtido através da construção permanente de um ambiente facilitador e estruturado e acolhedor, abrangendo várias modalidades de tratamento ${ }^{6}$.

Ademais, deve ter um projeto terapêutico do senviço que leve em consideração as diferentes contribuições técnicas dos profissionais dos CAPS, as iniciativas de familiares e usuários e o território onde se situa, com sua identidade, sua cultura local e regional ${ }^{6}$.

Os trabalhos de inserção cultural tais como reabilitações psicossociais devem ser voltados para o cidadão e nele este vai encontrar oportunidades de trocas afetivas, simbólicas e materiais capazes de favorecer vínculos e interação, e executar trabalhos de prevenção para o uso abusivo e/ou dependência de álcool bem como outras drogas.

Essas ações poderão contribuir para o fortalecimento e a estruturação de uma rede de atenção integral aos usuários de álcool e drogas e as suas famílias orientadas pela concepção ampliada da redução de danos articulada com outras redes sociais de saúde. Isto constitui, na atualidade, um importante desafio para saúde pública. 
É de grande relevância compreender de que modo são operadas as práticas de cuidado em saúde mental e como os dispositivos acolhimento e vínculo são capazes de transformar o cotidiano das práticas de atendimento no CAPS.

Esse estudo tem como objetivo compreender o modelo de cuidado em saúde em um CAPSad de acordo com a percepção dos usuários, visando entender a realidade dos sujeitos abordados. Com base nessa compreensão, apreendemos as concepções de cuidado valendo-se dos dispositivos: acolhimento, vínculo e responsabilização, formulados pelos usuários. Portanto, a abordagem será qualitativa, porquanto o objeto envolve dimensões subjetivas relacionadas aos cuidados dos profissionais para com os usuários do sistema.

Em consonância com o exigido, esta pesquisa foi submetida à análise do Comitê de Ética em Pesquisa (CEP) da Universidade Estadual do Ceará.

\section{Metodologia}

Trata-se de um estudo descritivo com abordagem qualitativa. Esse tipo de abordagem requer como atitudes fundamentais a abertura, a flexibilidade, a capacidade de observação e de interação com o grupo de investigadores e com os autores sociais envolvidos ${ }^{8}$.

A pesquisa foi realizada no município de Fortaleza no Centro de Atenção Psicossocial (CAPSad), destinado a usuários de álcool e drogas da Secretaria Executiva Regional IV (SER IV), com os usuários etilistas, no período de março a maio de 2012.

Nesse CAPS, os usuários são atendidos em regime de atenção diária. Há atendimentos individuais, coletivos e oficinas terapêuticas.

Houve participação de oito usuários, pois em virtude de repetição das respostas houve saturação teórica.

O critério de inclusão foi participantes que estavam em atendimento no CAPSad por mais de seis meses no período do estudo. Como critérios de exclusão foram considerados: os usuários que não estavam em acompanhamento contínuo no CAPSad, os que estavam iniciando o tratamento e os que não estavam em condições de responder a pesquisa.

Para a coleta de informações procedemos a entrevistas semi-estruturadas e observação sistemática, realizadas com base em um roteiro de questões previamente elaboradas de acordo com os objetivos da pesquisa.

A etapa de coleta de dados ocorreu após a aprovação do processo n 10338374-3 pelo Comitê de Ética em Pesquisa (CEP) da Universidade Estadual do Ceará (UECE). Todos os participantes da pesquisa foram esclarecidos acerca da pesquisa e assinaram o Termo de Consentimento Livre e Esclarecido.

As entrevistas foram gravadas e em seguida transcritas para as anotações gerais (diário de campo) para maior fidedignidade às informações, construindo uma condição fundamental para a realização da pesquisa.

Para a análise do material das entrevistas, dos documentos, e dos registros das observações, foram utilizadas as proposições de Bardin?.

A análise de conteúdo parte de uma literatura de primeiro plano para atingir um nível mais aprofundado. As respostas dos participantes foram categorizadas, sendo descoberta a saturação de ideias com significados similares que fizeram surgir as seguintes categorias: Fluxo do usuário alcoolista na efetivação do atendimento no CAPSad; A relação entre o profissional de saúde do CAPSad e o usuário alcoolistas; Orientações dos profissionais do CAPSad para o usuário alcoolista; Percepção dos usuários alcoolistas desenvolvidas nas oficinas terapêuticas; Participação dos usuários alcoolistas no projeto terapêutico ${ }^{9}$.

Com a finalidade de preservar a identidade dos participantes, cada um deles recebeu uma identificação que os distingue no relatório de pesquisa, assim especificada: U1, U2,.. U8.

\section{Resultados e discussões}

Quanto às características dos participantes, destacamos predominantemente idade acima dos 38 anos; terem segundo grau incompleto; sete serem do sexo masculino e apenas uma do feminino; com mais de dois anos de tratamento no serviço.

Ao chegarem ao CAPSad, os usuários, com horário pré-agendado, são recepcionados e dão a ideia de reconhecer a importância do serviço e, parcialmente, o aspecto de sua organização. Tal fato é demonstrado nas falas a seguir:

Primeiro passa pela recepção. Assina de acordo com o horário marcado aí espera uma das meninas chegarem, Dra. $X$ e $Y$, pra poder dar início ao trabalho no horto, que ficaram agendados semanalmente (U1). 
Pra mim, me sinto é em relação ao tratamento que você diz... [...] é, em relação ao tratamento me sinto muito segundo percebemos não tenho nada que reclamar não, é ótimo, excelente graças a Deus, tô me sentindo ótimo... muito bem (U2).

Os participantes reconhecem que os funcionários da recepção prestam um bom acolhimento. A primeira abordagem é primordial à chegada do paciente ao CAPS, a maneira como ele é recebido, acolhido na unidade.

Ótimo até agora tá bem... também cheguei aqui há pouco tempo mais é muito bom. Dra. $X$ é uma pessoa muito boa dar força e isso ajuda muito no tratamento, a gente vai mais ligeiro aqui é bom tem uns amiguim né é bom! (U3).

Evidenciamos aqui o grau de comprometimento dos profissionais que se doam em busca de uma resposta satisfatória ao tratamento.

A soma dos agenciadores do ser humano, a preocupação com o cuidado e o respeito com que cada um tem do mundo que rodeia ficam a cargo da responsabilização diante dos desafios do processo saúde/doença ${ }^{10}$.

A existência de diálogo entre o profissional e o usuário é importante na recuperação do usuário, pois há uma escuta sem julgamento, com consequente ajuda no seu percurso no tratamento.

Passa pela recepção, assina, faz atividade e vai embora né. Bem graças a Deus nos meses que tou aqui né recebi muito bem (U4).

Aqui de início logo que a gente chega a gente passa por uma triagem é encaminhada a um psicólogo ai [...] depois eles encaminham para os grupos que agente participa aqui [...] depois passa pelo psiquiatra também pra saber se precisa tomar algum medicamento (U5).

O atendimento é bem acompanhado pelo usuário que segue atento a todos os passos para início do trabalho. Acolher é receber bem, ouvir a demanda de forma a compreendê-la e solidarizar- se com ela ${ }^{11}$.

Observa-se uma relação de amizade, bem como um novo elo, desenvolvidos no CAPS. Como divulgado, o alcoolismo é uma doença que afasta o ser do meio social. Dessa forma, estar no CAPS, construir novas amizades e contar com a ajuda dessa entidade induz o usuário a se tornar um sujeito ativo no processo de formulação da sua saúde.

Bem, porque apesar deles serem pessoas, os profissionais serem excelentes, além de bons profissionais, os colegas também novas amizades que a gente faz e pra gente, né? Como aluno, né? Como podemos dizer? Eu acho ótimo, né? e pra mim tem sido de grande proveito (U1).

Ótimo! Ótimo! Primeiro dia eu conheci alguns amigos, tudo gente muito boa. A amizade tá sendo proveitosa, iniciada agora, né? Ta sendo muito bom (U2).

A este respeito, o diálogo é muito importante e deixa transparecer que para cuidar do outro fazemos uma aliança de zelo primeiramente e depois esta aliança se torna algo libertador, motivo de muita paz ${ }^{12}$.

Eu considero assim uma amizade, né? Que tem o bem da gente, pra gente poder se esforçar e deixar essas coisas, né? Que isso não é muito bom, né? A pessoa, né? Tem que ser uma pessoa seria, né? Isso não tem futuro pra ninguém e aqui no CAPS eu tô indo pra frente, se Deus quiser. É muito bom aqui, Ave Maria é bom demais (U3).

Nesse enfoque, fica clara a relação do vínculo profissional/usuário, de construção dessa relação de amizade e confiança baseada no vínculo.

A pessoa que sofre com o problema do alcoolismo experimenta inúmeras perdas e uma delas é o ciclo de amizades. Então, o profissional passa a ser aquela pessoa com a qual ele tem mais aproximação. Como no relato ora exposto, 0 profissional passa a ser um amigo, um aliado que está junto dele na busca pelo seu tratamento.

O vínculo confere segurança aos usuários, permitindo que os trabalhadores do serviço os conheçam para melhor estabelecer as prioridades na atenção à sua saúde ${ }^{13}$. 
Entretanto, nas falas dos entrevistados, o acolhimento apresenta-se de forma marcante, ao evidenciar uma preocupação, uma escuta, uma responsabilização do profissional para com o usuário.

Ótimo, bom demais. Só em a gente chegar aqui, né? TÊ nada difícil, né? Faz limpeza ai e tudo... (U4).

É tudo muito interagido, aqui não deixa nada a desejar por parte dos profissionais. Às vezes quem deixa a desejar é o próprio paciente, mais em relação aos funcionários é tudo cem por cento (U5).

Pode-se observar que o sujeito não é um sujeito passivo, existe uma integração entre o profissional e o paciente. O nível de satisfação é cem por cento.

Olha, uma coisa assim, como eu posso te dizer? !ue não é familiar, mais o atendimento aqui é uma coisa muito séria (U6).

Embora o paciente reconheça o ambiente como não familiar, deixa explícito que existe muito comprometimento do profissional para com o usuário.

A relação é ótima, acho super bem, eles tratam a gente bem, fala pra gente tomar o remédio na hora certa. Aqui agente faz varias coisas, tem o futebol, vou agora já já, eu vou pro futebol [...] bola, jogo e eu gosto muito (U7).

Foi possível constatar a preocupação dos profissionais quando o paciente está fora da unidade, por exemplo, se ele tomou a medicação. Isto é um pequeno detalhe, mas para o paciente faz toda a diferença, pois talvez no meio familiar onde ele se encontra não haja essa preocupação. Então, na sua condição de doente no lar, isso ajuda na busca de um melhor manejo e adaptação do seu tratamento.

A responsabilização do profissional para com o estado de saúde do paciente é um dos elementos essenciais para um efetivo acolhimento ${ }^{12}$. Para os usuários que aderiram ao tratamento no CAPS, o acolhimento corresponde às suas expectativas quanto às orientações recebidas dos profissionais.

Com certeza aqui eles tratam a gente muito bem [...] dão uma maior força mesmo, só se a pessoa não quiser ser gente, né? Aqui é um canto muito bom! (U1).

Apreende-se nessa categoria, que é com os profissionais que a maioria dos pacientes encontra esperanças, se veste de afetos e produz valores.

É possível constatar a preocupação do profissional quando o paciente está fora da unidade.

Bom, as oficinas são por grupo e, no caso, eu tô participando do ampliando movimento, que é o jogo [...] e estou participando do futebol e de uma massagem dia de Segunda-feira (U2).

O ser humano é um ser de participação e nasceu para viver em sociedade, trabalhar e estabelecer relações em grupo. Por isso, todas as atividades administradas pelos responsáveis do CAPS se enquadram àqueles pacientes que vivenciam os problemas, vão lá em busca de um tratamento, de uma terapêutica eficaze, assim, se empenham em todas as atividades propostas.

O participante menciona a negligência de alguns pacientes em relação ao seu tratamento, porém ressalta a gentileza dos profissionais em lidar com estas circunstâncias.

Bom! Eu acho ótimo, né? Agora, com exceção de certas pessoas que querem as vezes bagunçar o negócio, mais assim mesmo os profissionais são pessoas eficientes e consegue desdobrar de uma maneira que não prejudique a nenhum dos lados (U1).

Na Portaria do Sistema Nacional de Assistência Social-SNAS 189/1991, as oficinas terapêuticas são descrita como atividades grupais de socialização, expressão social. Desta forma, os CAPSad devem se utilizar dos recursos terapêuticos disponíveis para promover, o mais amplamente possível, a reabilitação psicossocial e a reinserção social dos seus usuários ${ }^{6}$. 
Muito bom a gente ocupa a cabeça da gente. É todo mundo muito unido, é muito bom mermo. Eu comecei no horto pra cuidar das plantas, ajeitar direitinho, né? Participei da oficina, a gente faz artesanato, todo mundo junto, todo mundo unido, é uma família, né? Tudo é fácil assim você queira não existe nada difícil não. Assim eu acredito (U2).

É possível notar a importância atribuída por esse usuário à terapia. Esta lhe propicia equilíbrio, possibilitando harmonização no seu interior, seja no cuidado com as plantas do horto, no artesanato, seja com o ambiente onde ele se encontra.

Chega aí, faz limpeza tem nada difícil não pra gente fazer não. Eles dizem como é pra gente fazer. Tudo que eles querem agente faz aí [... tem nada difícil não... tudo fácil (U3).

Tem uma variedade, aqui tem horto, tem artes, tem marcenaria sabe. [...] é bem completa a equipe, tem uma variedade, a pessoa só fica em uma se quiser, senão fica em varias durante a semana. É muito bom mesmo desenvolve várias parte do subconsciente (U4).

Para este entrevistado, as atividades terapêuticas são essenciais no tratamento uma vez que ele trabalha o equilíbrio emocional, por meio dessas atividades.

Os recursos terapêuticos não fazem outra coisa senão resgatar essa memória terapêutica da nossa própria tradição. A medicina hoje reconhece que a cura não se dá somente pela química dos remédios, mas leva em consideração o ser humano como um todo. Os pacientes demonstram bem-estar em realizar as atividades terapêuticas, de forma que a cura pode ser considerada um processo global, envolvendo o ser humano como um todo e não tão-somente a parte enferma ${ }^{12}$.

Quanto à participação do usuário no projeto terapêutico, evidencia-se o esforço do paciente ao perder forças, mas ao assumir essa responsabilidade para si ele retoma reconhecendo a força do CAPS em sua vida.

Com certeza, em todos os sentidos, né? como já precisei e falhei várias, eu mesmo soube me corrigir e deu certo... e não estou arrependido, estou muito satisfeito. Bom, o que eu gostaria de acrescentar além do tratamento que a gente tem aqui, que antes pra quem não conhece como antes, eu não conhecia, né? Não tinha a mínima idéia do que significava essa palavra CAPS e que da minha parte, falando por mim, né? To me sentindo muito bem e o que depender de mim nesse sentido de ajuda, né? eu faço de bom grado, de coração né (U1).

No CAPS, a proposta de cuidado é baseada em ações destinadas à reabilitação psicossocial, na busca da autonomia de cada usuário. A reabilitação é entendida como um conjunto de ações que visam aumentar a habilidade do indivíduo, diminuindo o dano causado pelo transtorno mental ${ }^{14}$.

Ora! Com certeza absolutamente, né? Sim, é maravilhoso a gente participar de uma entidade dessa, te ajuda na tua saúde, te ajuda no teu comportamento, te ajuda no teu relacionamento entre as pessoas, é ótimo, muito bom. Eu aconselho os jovens, as pessoa, né? Que tem esse problema, né? Vem pro CAPS que é muito bom, apesar de estar iniciando, mas já dá pra saber [...] o acolhimento é muito bom, só tenho a agradecer (U2).

É evidente que a participação dos pacientes passa pelo intercurso das atividades, onde estão inseridas as oficinas, mas o que ele relata diz respeito, principalmente, ao acolhimento, de sentir-se bem no ambiente.

Conforme observamos, a eficácia dos métodos utilizados pelo CAPS desenvolve um novo equilíbrio humano no âmbito corporal e espiritual e os profissionais buscam construir o equilibrio de trabalho com autocontrole e moderação.

Com certeza é muito bom mesmo, né? Isso ai que eles faze com a gente eu acho uma maravilha isso que eles faze com as pessoas que têm esse problema, né? (U3).

Dessa forma, a análise do significado do acolhimento dos usuários no CAPS é satisfatória e nos propiciou mostrar a importância do empenho dos profissionais quando se pretende um atendimento integral. $O$ acolhimento é um instrumento poderoso e pode influenciar positivamente no tratamento. 
Com certeza... pra início de toda recuperação do ser humano... primeiro o querer dele... porque se for do profissional, nunca ele chega ao ponto de recuperação. Rapaz, sobre o acolhimento, aqui não aqui falta mais apoio, não sei se do governo ou prefeitura. Por aqui, o profissional tira do próprio bolso pra ajudar no material das terapias com agente [...] falta apoio governantes, aqui tem salvado vidas. 0 acolhimento aqui é ótimo. Falta interesse das entidades governamentais (U4).

Nesse discurso, o participante reconhece a falta de apoio dos governantes e de mais envolvimento da sociedade e também, das entidades. Portanto, há um desafio para poucos, no caso, os profissionais que se dão por inteiro para auxiliar na recuperação da saúde.

De modo geral, os principais limites decorrentes da falta de prioridade dada a uma política de saúde integral dirigida ao consumidor de álcool e outras drogas podem ser observados a partir dos impactos econômico e social que têm recaído sobre o SUS. Tais impactos se refletem tanto nos seus custos diretos, quanto na impossibilidade de resposta de outras pastas governamentais, de forma a impactar positivamente na redução do consumo de drogas, no resgate do usuário do ponto de vista da saúde e não tão-somente moralista ou legalista, e em estratégias de comunicação que reforçam o senso comum de que todo consumidor é marginal e perigoso para a sociedade ${ }^{6}$.

Com certeza, o meu tratamento depende muito da minha força de vontade, né? Pra mim poder chegar onde eu quero. Eu sei que estou curado, mas é pra não voltar, ter nenhum problema [...] 0 acolhimento aqui é satisfatório (U5).

O usuário reconhece sua responsabilidade em relação ao tratamento, mas ressalta que precisa do controle do profissional para evitar uma possível recaída. Quando o paciente sente que todo o êxito do tratamento dependerá dele, a responsabilização é compartilhada e ele assume autonomia no processo saúde/doença. A autonomia significa autocriação. Para ser efetiva, a recuperação do paciente, precisa ser algo vivenciado por ele próprio como uma criação sua ${ }^{15}$.

\section{Considerações Finais}

Por meio das entrevistas realizadas no Centro de Atenção Psicossocial Álcool e outras Drogas, a satisfação dos usuários que procuram tratamento nessa unidade é visível nas suas representações. Laços de amizades se fundem em uma lógica acolhedora entre os profissionais e os usuários, evidenciada na confiança do profissional, com a consciência da sua responsabilidade no tocante ao tratamento.

Quanto ao fluxo do usuário na efetivação do atendimento no CAPSad, observa-se em uma das categorias da entrevista a consciência da responsabilidade do Estado na reformulação das políticas públicas. Ademais, a lei existe, os direitos também. Entretanto, a falta de implementação dessas ações é bem clara e não acontece em virtude da carência de meios adequados para o atendimento eficaz tais como estrutura física, material para manuseio nas oficinas terapêuticas, falta de contratação de profissionais em todos os âmbitos da saúde que poderiam atuar consoante a reforma psiquiátrica brasileira.

Os usuários do CAPSad lamentam o descuido ou a falta de comprometimento do governo que idealiza um programa tão eficaz cujo modelo está lá proposto, contudo, que na prática está muito longe ainda de acontecer a contento.

Os dependentes, em momento algum, se referem ao próprio vício ou a qualquer dependência que venham a sofrer. Eles esperam ser acolhidos pelo profissional na perspectiva de quem sofre de preconceitos e se envergonha de procurar sua cura, embora precise ser cuidado. Se de um lado o alcoolismo é entendido como uma doença, de outro pode ser visto pejorativamente. Isto pode intimidá-lo a se reconhecer como um doente alcoólico.

Nesse desafio o modelo de reabilitação encontrado no CAPSad é satisfatório. Ademais, os dispositivos, acolhimento, vínculo, consistem na responsabilidade compartilhada entre profissional/usuário, com vistas potencializar a resolubilidade dos atendimentos.

Conforme os resultados apontam, o enfrentamento de uma dependência química de drogas, sejam elas lícitas ou ilícitas, não perpassa somente pelos muros dos CAPSad. Este é um problema da saúde pública, não especificamente do município de Fortaleza-CE, mas de âmbito nacional. No entanto, essa representação foi associada por um dos entrevistados que reconhece que a responsabilidade não está somente nos profissionais e usuários, mas no âmbito de governo e sociedade. 
No tocante ao modelo de saúde no CAPSad, quanto ao vínculo, acolhimento, responsabilização, os usuários nos mostraram a contribuição desses dispositivos para seu tratamento.

Como evidenciado pelos relatos, eles agradecem enfaticamente aos profissionais por serem reconhecidos não somente como doentes, mas como seres humanos.

Com efeito, o acolhimento no CAPSad como instrumento de trabalho envolve todos os membros da equipe, propiciando, assim, a resolubilidade da assistência.

\section{Referências Bibliográficas}

1. INPAD - Instituto Nacional de Ciência e Tecnologia para Políticas do Álcool e Outras Drogas. II LENAD - Levantamento Nacional de Álcool e Drogas. Consumo de alcool no Brasil: tendências entre 2006/2012 [Internet]. São Paulo: INPAD; 2013 [acesso em: 08 jul 2014]. Disponível em: http://inpad.org.br/wp-content/uploads/2013/04/LENAD_ALCOOL_Resultados-preliminares.pdf 2. GALLASSI, A.D; ALVARENGA, P.G; ANDRADE, A.G.; COUTTOLENC, B.F. Custos dos problemas causados pelo abuso do álcool. Rev. psiquiatr. clín. [online]. 2008, vol.35, suppl.1 [cited 2014-06-08], pp. 25-30 . Disponível em: http:/l www.scielo.br/scielo.php?script=sci_arttext\&pid=S0101-60832008000700007\&lng=en\&nrm=iso.

3. NEVES, D. P. Alcoolismo: acusação ou diagnóstico? Cad. Saúde Pública, Rio de Janeiro, v. 20, n. 1, p. 7-36, 2004. 4. MOTA, L. A. A dádiva da sobriedade: a ajuda mútua nos grupos de alcoólicos anônimos. São Paulo: Paulus, 2004.

5. ALVES, V. S. Modelos de atenção à saúde de usuários de álcool e outras drogas: discursos políticos, saberes e práticas. Cad. Saúde Pública, Rio de Janeiro, v. 25, n. 11, 2009.

6. BRASIL. Ministério da Saúde. A política do Ministério da Saúde para a atenção integral a usuários de álcool e outras drogas. Brasília, 2003.

7.CARDOSO, C.; SEMINOTTI, N. O grupo psicoterapêutico no Caps. Ciênc. Saúde Coletiva, Rio de Janeiro, v. 11, n. 3, p. 775-783, 2006.

8. MINAYO, M. C. S. O desafio do conhecimento: pesquisa qualitativa em saúde. 9. ed. São Paulo: Hucitec, 2006.

9. BARDIN, L. Análise de conteúdo. Tradução de Luís Antero Reto e Augusto Pinheiro. Lisboa: Edições 70, 2010.

10. SANTOS, A. M.; ASSIS, M. M. A. Da fragmentação à integralidade: construindo e (des) construindo a prática de saúde bucal do Programa de Saúde da Família (PSF) de Alagoinhas, BA. Ciênc. Saúde Coletiva, Rio de Janeiro, v. 11, n. 1, p. 53-61, 2006.

11. CAMPOS, G. W. S. Saúde Paidéia. São Paulo: Hucitec, 2003.

12. BOFF, L. Saber cuidar: ética do humano: compaixão pela Terra. Petrópolis, RJ: Vozes, 1999.

13. LIMA, R. A. S.; AMAZONAS, M. C. L. A.; MOTTA, J. A. G. Incidência de stress e fontes estressoras em esposas de portadores da síndrome de dependência do álcool. Estudos de Psicologia, Campinas, v. 24, n. 4, p. 431-439, out./dez. 2007. 14. MIELKE, F. B.; KANTORSKI, L. P.; JARDIM, V. M. da R.; OLSCHOWSKY, A.; MACHADO, M. S. O cuidado em saúde mental no CAPS no entendimento dos profissionais. Ciênc. Saúde Coletiva, Rio de Janeiro, v. 14, n. 1, p. 159-164, 2009. 15. MARTINS, A. Biopolítica: o poder médico e a autonomia do paciente em uma nova concepção de saúde. Interface (Botucatu), Botucatu, v. 8, n. 14, fev. 2004. 


\section{Maria Zilmar Lima}

Endereço para correspondência - Rua: Jorge Acurcio, № 600, ap 206, Bairro: Vila União, CEP 60410-802, Cidade: Fortaleza, CE, Brasil.

E-mail: zilmar.lima@bol.com.br

Lattes: http://lattes.cnpq.br/1051660551293521

Edilson Martins Rodrigues Neto - edilsonmrneto@hotmail.com

Marcia Oliveira Coelho -oc.marcia@gmail.com

Lidia Audrey Rocha Valadas - lidiavaladas@gmail.com

Mara Assef Leitão Lotif - mara_lotif@hotmail.com

Enviado em 19 de setembro de 2014. Aceito em 07 de abril de 2015. 
